FORUM MINIREVIEW

\title{
The Non-neuronal Cholinergic System
}

\section{Roles of Muscarinic Acetylcholine Receptors in Interleukin-2 Synthesis in Lymphocytes}

\author{
Yasunobu Okuma* and Yasuyuki Nomura \\ Department of Pharmacology, Graduate School of Pharmaceutical Sciences, Hokkaido University, Sapporo 060-0812, Japan
}

Received August 11, 2000 Accepted August 11, 2000

\begin{abstract}
Receptors for many neurotransmitters including catecholamines and acetylcholine (ACh) have been detected on the cell surface of lymphocytes. It has been demonstrated that a human T cell line synthesizes ACh and suggested that ACh may be an autacoid modulating $\mathrm{T}$ cell-dependent immune responses. However, the biochemical interactions of the ACh system with the immune system have not been elucidated in detail. We have shown that $\mathrm{m} 1$ and $\mathrm{m} 2$ muscarinic receptor mRNAs are expressed in human peripheral blood lymphocytes and in human $\mathrm{T}$ cell line Jurkat cells and that pretreatment of these cells with a muscarinic receptor agonist enhances interleukin-2 (IL-2) production. We also postulated possible intracellular signaling pathways via which muscarinic receptors regulate IL-2 production in Jurkat cells. The findings suggest that $\mathrm{M}_{1}$ muscarinic receptors are involved in muscarinic receptor-mediated enhancement of IL-2 production in Jurkat cells and that the transcription factor AP-1 and pathways via mitogen-activated protein kinase (MAPK) / extracellular signal regulated protein kinase and c-Jun N-terminal kinase, but not via p38 MAPK, may be involved in the muscarinic receptor-mediated enhancement of IL-2 production. Our findings demonstrate a neuro-immune interaction through muscarinic receptor signaling in immune cells.
\end{abstract}

Keywords: Neuroimmune interaction, Muscarinic receptor, Interleukin-2, Jurkat cell

Several studies suggest that the nervous system regulates immune function. Electron microscopic studies have demonstrated that vagus nerves are present in lymphoid tissues such as the spleen and thymus and that nerve terminals form synaptic contacts with lymphocytes (1). In addition, lymphocytes possess various neurotransmitters and neuropeptide receptors such as $\beta$-adrenoceptors, muscarinic acetylcholine (ACh) receptors, 5-hydroxytryptamine-1 receptors and type B cholecystokinin receptors. It is known that the $\beta$-adrenoceptor- $\mathrm{G}_{\mathrm{s}}$-adenylyl cyclase system is involved in the inhibitory regulation of interleukin (IL)-2 production and thus the proliferation of T cells (2). Despite several studies on the functional role of the $\beta$-adrenergic system, details of the biochemical interactions of the muscarinic ACh system with the immune system (3) have not been elucidated. Lymphocytes have been shown to synthesize ACh (4), and nicotinic and muscarinic ACh receptors

*Corresponding author. FAX: +81-11-706-4987

E-mail: okumay@pharm.hokudai.ac.jp are present on the surface of lymphocytes $(5,6)$. We demonstrated that the activation of muscarinic ACh receptors increases at the cytoplasmic concentration of $\mathrm{Ca}^{2+}$ in Jurkat cells, a human leukemic helper T lymphocyte line (7). Recently, it has been reported that $\mathrm{ACh}$ attenuated the release of cytokines tumor necrossis factor (TNF), IL-1 $\beta$, IL- 6 and IL-18 in lipopolysaccharide-stimulated macrophages and that the vagal stimulation inhibited TNF synthesis in the liver (8). These reports suggest that ACh may be an autacoid modulating immune responses.

IL-2 is the first in a series of lymphocytotrophic hormones, and it has a pivotal role in the generation and regulation of immune responses. Activation of TCR/CD3 complexes induces IL-2 production in Tcells, and some immunosuppressants, such as cyclosporin A and FK-506, inhibit this IL-2 production (9). Cyclosporin A- and FK506-binding proteins, identified as immunophilines (cyclophilins and FKBPs, respectively) (10), are targets for $\mathrm{Ca}^{2+}$ CaM-dependent phosphatase 2B, also known as calcineurin (11). However, the detailed mechanisms of IL-2 production 
and regulation are not clear.

Stimulatory role of muscarinic ACh receptors in T cell
antigen receptor-mediated IL-2 production in human
peripheral blood lymphocytes (hPBL)
Pretreatment of hPBL with $\mathrm{ACh}$ (in the presence of physostigmine) or oxotremorine-M (muscarinic agonist, Oxo-M) but not nicotine for $24 \mathrm{~h}$ enhanced phytohemagglutinin (PHA)-induced IL-2 production (Fig. 1). On the other hand, ACh or Oxo-M alone did not affect IL-2 production. Anti-CD3 mAb-induced IL-2 production was also enhanced by Oxo-M (62\%), so that it was similar to PHA-induced IL-2 production (69\%). Using CD3-positive T cells prepared by a positive panning selection from hPBL, pretreatment with Oxo-M enhanced PHA-induced IL-2 production (5). These findings suggest that activation of muscarinic receptors enhances $\mathrm{T}$ cell antigen receptor /CD3-induced IL-2 production.

\section{Possible intracellular signaling pathways of muscarinic receptors that regulate IL-2 production in human $T$ cell line Jurkat cells}

The presence of muscarinic receptors on human lymphocytes has been demonstrated by several studies using radioligand binding assays $(12,13)$. We detected $\mathrm{m} 1$ and $\mathrm{m} 2$ muscarinic receptor mRNA subtypes in Jurkat cells as well as in hPBL (5). On the other hand, Ewa and Nordberg (14) showed that $\mathrm{m} 3, \mathrm{~m} 4$ and $\mathrm{m} 5$ muscarinic receptor mRNAs were expressed in purified human T cells, while $\mathrm{m} 1$ and $\mathrm{m} 2$ subtypes were not detected. In addition, they reported that both $\mathrm{m} 3$ and $\mathrm{m} 5$ subtypes were expressed in Peer cells, a

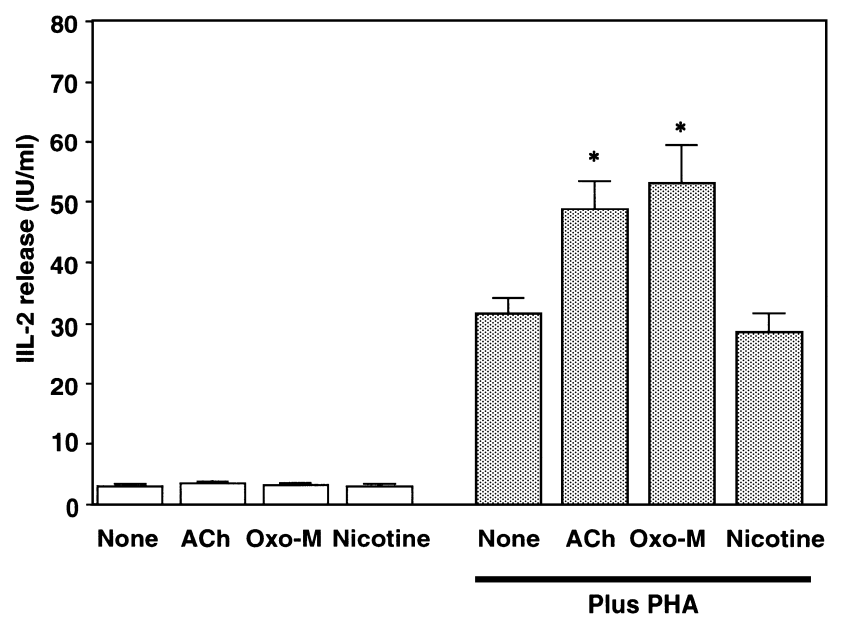

Fig. 1. Effects of cholinergic agonists on PHA-induced IL-2 production in hPBL. hPBL were incubated with cholinergic agonists ( $1 \mu \mathrm{M}$ ACh in the presence of $100 \mu \mathrm{M}$ physostigmine, $1 \mu \mathrm{M}$ Oxo-M, $1 \mu \mathrm{M}$ nicotine) for $24 \mathrm{~h}$. Then $10 \mu \mathrm{g} / \mathrm{ml}$ PHA was added and cells were further incubated for $24 \mathrm{~h}$. The amounts of IL-2 released into the medium were analyzed by ELISA. Results are expressed as the mean \pm S.E.M. in all four experiments. ${ }^{*} P<0.05$ vs none. human leukemic T cell line. Although Kawashima et al. (15) showed the expression of $\mathrm{m} 4$ and $\mathrm{m} 5$ subtype mRNAs in the CEM, MOLT-3 and Jurkat cells, m3 subtype mRNA expression was detected in both CEM and MOLT-3, but not in Jurkat cells. These differences are probably due to the experimental conditions of the $\mathrm{T}$ cells in the laboratory (16).

We detected $\mathrm{m} 1$ and $\mathrm{m} 2$ receptors in Jurkat cells and found that stimulation of these receptors with Oxo-M enhanced both IL-2 production and promoter activity induced by phorbol 12-myristate 13-acetate (PMA)/A23187 (calcium ionophore). This enhancement was inhibited by 4DAMP ( $\mathrm{M}_{1}$ - and $\mathrm{M}_{3}$-receptor antagonist) and atropine (non-selective muscarinic receptor antagonist), while AFDX116 ( $\mathrm{M}_{2}$-receptor antagonist) further enhanced IL-2 production (16). Therefore, stimulation of $M_{1}$ receptors alone enhanced IL-2 production and stimulation of $\mathrm{M}_{2}$ receptors alone may have inhibited it, although stimulation of both types of $\mathrm{M}_{1}$ and $\mathrm{M}_{2}$ receptors together appeared to enhance it. The IL-2 promoter activity is regulated by the 300-bp region adjacent to the transcription initiation site (17). This region contains specific binding sites for various transcription factors including activation protein (AP)-1, nuclear factor (NF)- $\kappa \mathrm{B}, \mathrm{NF}-\mathrm{AT}$ and Oct-1, and cooperation of these factors is required for maximal activation of the IL-2 promoter (18). The stimulation of $\mathrm{M}_{1}$ receptors (with Oxo-M in the presence of $\mathrm{M}_{2}$ antagonist AF-DX116) enhanced the PMA/A23187-induced binding activity to AP1 consensus sequences in the IL-2 promoter (Fig. 2) (16). The stimulation of $\mathrm{M}_{1}$ receptors did not modify the DNA binding of NF- $\kappa \mathrm{B}$, NF-AT or Oct-1. The findings suggest that the transcription factor AP-1 is involved in $\mathrm{M}_{1}$-receptor-mediated enhancement of IL-2 transcription in Jurkat cells.

It has been reported that signals from muscarinic receptors affect the mitogen-activated protein kinases (MAPKs) in various cells $(19,20)$. However, the effects of muscarinic receptor stimulation on the MAPKs cascades in lymphocytes have not been established. When $\mathrm{M}_{1}$ receptors were stimulated, the activities of MAPK/extracellular signal regulated protein kinase (ERK) and c-Jun N-terminal kinase (JNK) were increased, while p38 MAPK was not affected (16). The findings of this study indicate that ERK and JNK, but not p38 kinase, are involved in the $\mathrm{M}_{1}$-receptor-mediated enhancement of IL-2 production by stimulating AP-1 activity. There are some reports that MAPK signal transduction pathways are involved in IL-2 gene transcription in T cells: Ras, the JNK cascade, and one or more of AP-1 (21), raf-1, MAPK-extracellular signal-regulated kinase (MEK) 1 and ERK 1/2 (22). Therefore, ERK and JNK may activate AP-1 proteins via the activation of c-Fos and c-Jun, respectively.

In conclusion, muscarinic receptors in T cells play func- 
AP-1

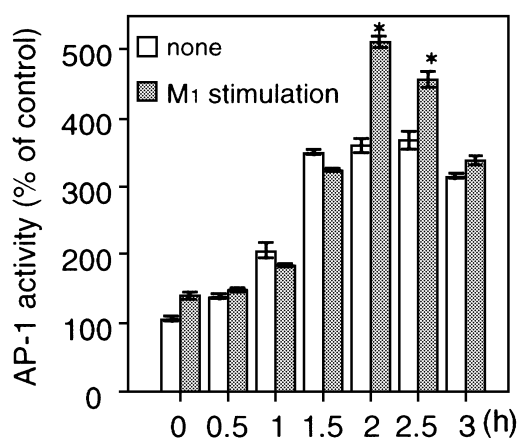

NF-AT

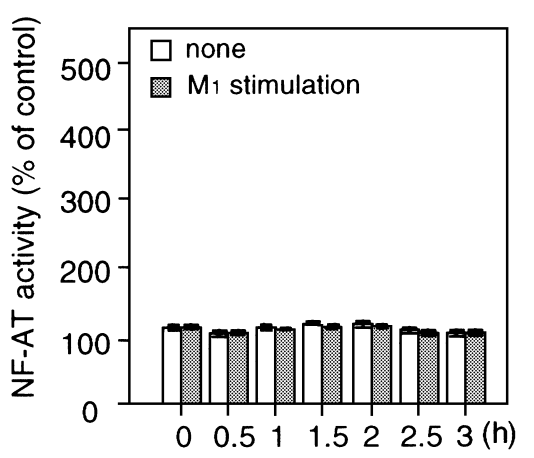

NF-KB

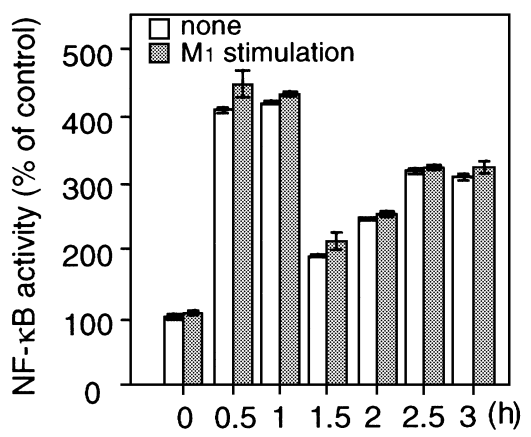

Oct-1

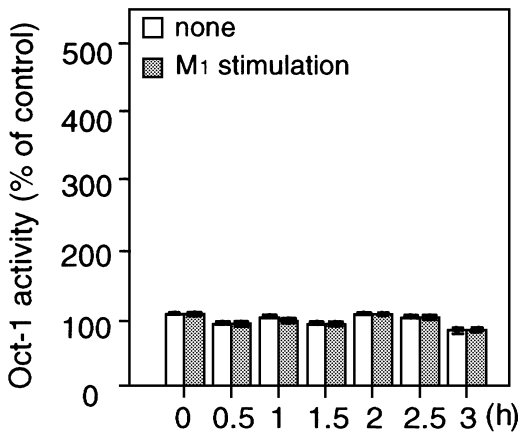

Fig. 2. Effect of $M_{1}$-receptor stimulation on PMA/A23187-induced AP-1, NF- $\kappa$ B, NF-AT and Oct- 1 consensus sequence binding proteins in Jurkat cells. Jurkat cells were treated with $100 \mu \mathrm{M}$ Oxo-M in the presence of $1 \mu \mathrm{M}$ AF-DX116, an $\mathrm{M}_{2}$ antagonist, for $1 \mathrm{~h}$ prior to treatment with $1 \mathrm{nM}$ PMA plus $500 \mathrm{nM}$ A23187. The band shift assays were performed using each nuclear extract. The quantities of each band are shown in a bar chart. ${ }^{*} P<0.05$ vs none.

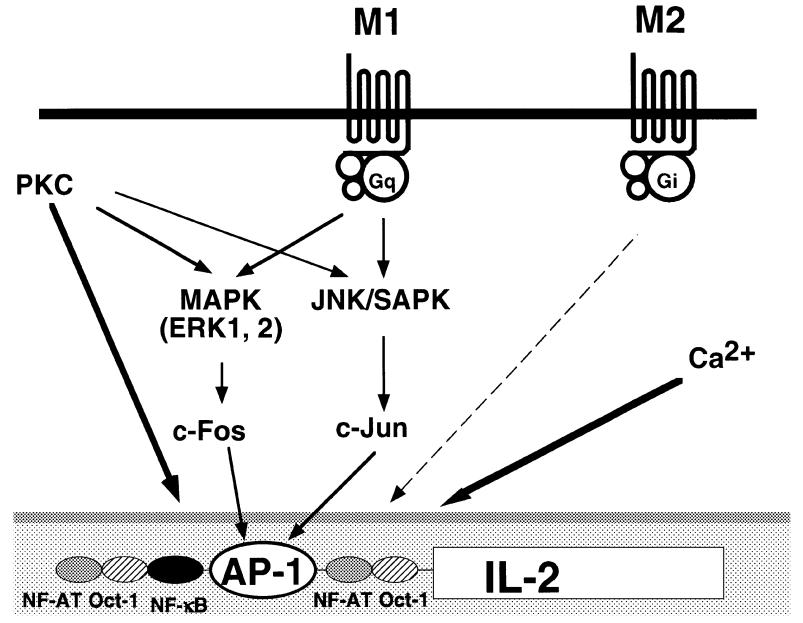

Fig. 3. Proposed role of muscarinic ACh receptors in the regulation of IL-2 production. Jurkat cells express $\mathrm{m} 1$ and $\mathrm{m} 2$ receptor mRNAs. Stimulation of $\mathrm{M}_{1}$ receptors enhances PMA/A23187-induced IL-2 production. AP-1 may be involved in this enhancement, and both MAPK and JNK also seem to be involved. $\mathrm{M}_{2}$ receptors may function to decrease the IL-2 production. SAPK: stress-activated protein kinase. tional roles in regulation of IL-2 synthesis. The transcription factor AP-1 and MAPK signal transduction pathways may be involved in the $\mathrm{M}_{1}$-receptor-mediated enhancement of IL-2 synthesis in Jurkat cells (Fig. 3). These findings show the existence of neuroimmune interactions through muscarinic receptor signaling in immune cells.

\section{RERERENCES}

1 Bulloch K: Neuroanatomy of lymphoid tissue: a review. In Neural Modulation of Immunity: Proceedings of an International Symposium Held Under the Auspices of the Princess Liliane Cardiology Foundation in Brussels, Belgium, October 27 \& 28, 1983, Edited by Guillemin R, pp 111 - 141, Books on Demand, New York (1985)

2 Kammer GM: The adenylate cyclase-cAMP-protein kinase A pathway and regulation of the immune response. Immunol Today 9, $222-229$ (1988)

3 Strom BT, Lane AM and George K: The parallel, time-dependent, bimodal change in lymphocyte cholinergic binding activity and cholinergic influence upon lymphocyte-mediated cytotoxicity after lymphocyte activation. J Immunol 127, 705 - 710 (1981) 
4 Fujii T, Tsuchiya T, Yamada S, Fujimoto K, Suzuki T, Kawahara $\mathrm{T}$ and Kawashima K: Localization and synthesis of acetylcholine in human leukemic T cell line. J Neurosci Res 44, 66 - 72 (1996)

5 Fujino H, Kitamura Y, Yada T, Uehara T and Nomura Y: Stimulatory roles of muscarinic acetylcholine receptors on $\mathrm{T}$ cell antigen receptor/CD3 complex-mediated interleukin-2 production in human peripheral blood lymphocytes. Mol Pharmacol 51, 1007 - 1014 (1997)

6 Sato KZ, Fujii T, Watanabe Y, Yamada S, Ando T, Fujimoto K and Kawashima K: Diversity of mRNA expression for muscarinic acetylcholine receptor subtypes and neuronal nicotinic acetylcholine receptor subunits in human mononuclear leukocytes and leukemic cell lines. Neurosci Lett 266, 17 - 20 (1999)

7 Kaneda T, Kitamura Y and and Nomura Y: Presence of $\mathrm{m} 3$ subtype muscarinic acetylcholine receptors and receptor-mediated increases in the cytoplasmic concentration of $\mathrm{Ca}^{2+}$ in Jurkat, a human leukemic helper T lymphocyte line. Mol Pharmacol 43, $356-364$ (1993)

8 Borovikova LV, Ivanova S, Zhang M, Yang H, Botchkina GI, Watkins LR, Wang H, Abumrad N, Eaton JW and Tracey KJ: Vagus nerve stimulation attenuates the systemic inflammatory response to endotoxin. Nature 405, $458-462$ (2000)

9 Schreiber SL: Chemistry and biology of the immunophilines and their immunosuppressive ligands. Science 251, 283 - 287 (1991)

10 Schreiber SL and Crabtree GR: The mechanism of action of cyclosporin A and FK506. Immunol Today 13, 136 - 142 (1992)

11 Clipstone NA and Crabtree GR: Identification of calcineurin as a key signalling enzyme in T-lymphocyte activation. Nature 357, $695-697$ (1992)

12 Strom BT, Lane AM and George K: The parallel, time-dependent, bimodal change in lymphocyte cholinergic binding activity and cholinergic influence upon lymphocyte-mediated cytotoxicity after lymphocyte activation. J Immunol 127, 705 - 710 (1981)

13 Eva C, Ferrero P, Rocca R, Funaro A, Bergarmasco B, Ravizza $\mathrm{L}$ and Genazzani E: $\left[{ }^{3} \mathrm{H}\right] N$-Methylscopolamine binding to muscarinic receptors in human peripheral blood lymphocytes charac- terization, localization on T-lymphocytesubsetsandage-dependent changes. Neuropharmacology 28, 719 - 726 (1989)

14 Ewa HL and Nordberg A: Muscarinic receptor subtypes in subpopulations of human blood mononuclear cells as analyzed by RT-PCR technique. J Neuroimmunol 68, 139 - 144 (1996)

15 Kawashima K, Fujii T, Watanabe Y and Misawa H: Acetylcholine synthesis and muscarinic receptor subtype mRNA expression in T-lymphocytes. Life Sci 62, 1701 - 1705 (1998)

16 Fujino $H$, Uehara $T$, Murayama $T$, Okuma $Y$, Ariga $H$ and Nomura Y: Extracellular signal regulated protein kinase and cJun $\mathrm{N}$-terminal kinase are involved in $\mathrm{m} 1$ muscarinic receptorenhanced interleukin-2 production pathway in Jurkat cells. Biol Pharm Bull 23, 1198 - 1205 (2000)

17 Fujita T, Shibuya H, Ohashi T, Yamanishi K and Taniguchi T: Regulation of human IL-2 gene: functional DNA sequences in the 5' flanking region for the gene expression in activated T lymphocytes. Cell 46, $401-405$ (1986)

18 Durand DB, Shawh J, Bush M, Replogle RE, Belageje R and Crabtree G: Characterization of antigen receptor response elements within the interleukin 2 enhancer. Mol Cell Biol 8, 1715 1724 (1988)

19 Winitz S, Russell M, Qian N, Gardner A, Dwyer L and Johnson GL: Involvement of Ras and Raf in the Gi-coupled acetylcholine muscarinic $\mathrm{m} 2$ receptor activation of mitogen-activated protein (MAP) kinase kinase and MAP kinase. J Biol Chem 268, $19196-19199$ (1993)

20 Mattingly RR and Macara IG: Phosphorylation-dependent activation of the Ras-GRF/CDC25Mm exchange factor by muscarinic receptors and G-protein $\beta \gamma$ subunits. Nature 382, $268-272$ (1996)

21 Faris M, Kokot N, Lee L and Nel AE: Regulation of interleukin2 transcription by inducible stable expression of dominant negative and dominant active mitogen-activated protein kinase kinase kinase in Jurkat T cells. J Biol Chem 271, 27366 - 27373 (1996)

22 Whitehurst $\mathrm{CH}$ and Geppert TD: MEK 1 and the extracellular signal-regulated kinases are required for the stimulation of IL-2 gene transcription in T cells. J Immunol 156, 1020 - 1029 (1996) 